\title{
Erratum to: Data mining for response shift patterns in multiple sclerosis patients using recursive partitioning tree analysis
}

\author{
Yuelin Li • Carolyn E. Schwartz
}

Published online: 21 December 2011

(C) Springer Science+Business Media B.V. 2011

Erratum to: Qual Life Res (2011) 20:1543-1553

DOI 10.1007/s11136-011-0004-7

The information in the Acknowledgments section in the original publication was incomplete. The first sentence should read: "This work was funded in part by a NARCOMS
Visiting Scientist Fellowship to Dr. Schwartz, which was supported through a Foundation of the Consortium of Multiple Sclerosis Centers grant from EMD Serono, Inc. NARCOMS is supported by the Consortium of Multiple Sclerosis Centers and its Foundation.”

The online version of the original article can be found under doi:10.1007/s11136-011-0004-7.

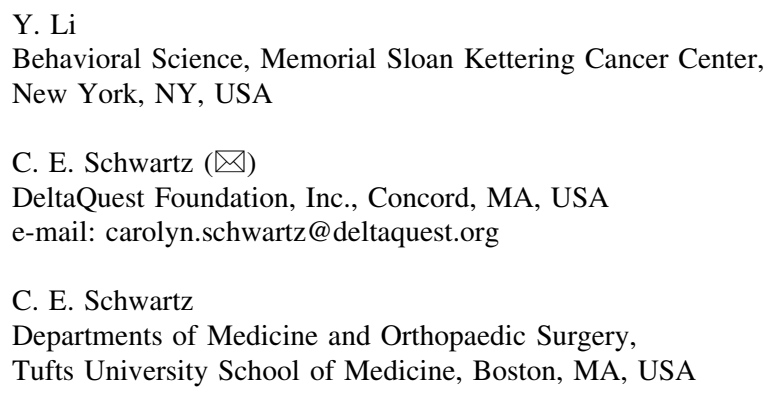

